\title{
PERENCANAAN STRATEGIS SISTEM INFORMASI MENGGUNAKAN METODE WARD AND PEPPARD (STUDI KASUS : DINAS KEPENDUDUKAN DAN PENCATATAN SIPIL KOTA TOMOHON)
}

\author{
Melisa Ervina ${ }^{1)}$, Chris Rudianto ${ }^{2)}$, dan Hanna Prillysca Chernovita ${ }^{3)}$ \\ ${ }^{1,2,3}$ Sistem Informasi, Fakultas Teknologi Informasi, Universitas Kristen Satya Wacana \\ 1,2,3 Jl. DR. O. Notohamidjojo No.1, Salatiga, 50711 \\ E-mail : 682015087@ student.uksw.edu ${ }^{1)}$, chris.rudianto@ uksw.edu ${ }^{2)}$, hanna.chernovita@uksw.edu ${ }^{3)}$
}

\begin{abstract}
ABSTRAK
Dinas Kependudukan dan Pencatatan Sipil (Disdukcapil) Kota Tomohon merupakan instansi pemerintahan yang memiliki kewenangan dalam bidang administrasi kenegaraan. Teknologi Informasi merupakan salah satu faktor yang mempengaruhi keberhasilan suatu organisasi. Untuk itu, dibutuhkan sebuah perencanaan strategis sistem informasi yang sesuai dengan kebutuhan bisnis serta tujuan organisasi. Pada Dinas Kependudukan dan Pencatatan Sipil Kota Tomohon sudah menerapkan Sistem Informasi dan Teknologi Informasi (SI/TI) dalam menunjang tugas kerja setiap harinya. Namun, pada Disdukcapil belum memiliki perencanaan strategis sistem informasi. Tujuan penelitian ini adalah untuk menyusun perencanaan strategis sistem informasi yang sesuai dengan visi misi instansi. Penelitian ini menggunakan metode Ward And Peppard dengan berbagai analisis seperti analisis SWOT, Value Chain, dan Mc Farlan Strategic Grid. Hasil dari penelitian ini adalah berupa portofolio perencanaan strategis sistem informasi yang sesuai dengan kebutuhan Disdukcapil.
\end{abstract}

Kata Kunci: Mc Farlan Strategic Grid, Sistem Informasi, SWOT, Value Chain, Ward and Peppard

\section{PENDAhUluAN}

Dinas Kependudukan dan Pencatatan Sipil merupakan unsur pelaksana Pemerintah Daerah di bidang Kependudukan dan Pencatatan Sipil yang dipimpin oleh Kepala Dinas dan berkedudukan di bawah dan bertanggungjawab kepada Bupati melalui Sekretaris Daerah. Dinas Kependudukan dan Pencatatan Sipil mempunyai tugas melaksanakan urusan rumah tangga Pemerintah Daerah dan tugas pembantuan di bidang Kependudukan dan Pencatatan Sipil.

Pada jaman Teknologi Informasi saat ini, dimana setiap organisasi yang ingin bertahan dan berkembang dibutuhkan pengimplementasian Sistem Informasi (SI) yang didukung dengan adanya Teknologi Informasi (TI) yang memadai. Penerapan teknologi informasi merupakan langkah yang sangat penting dalam sebuah organisasi. Dengan adanya teknologi informasi pada sebuah organisasi, maka aktivitas bisnis yang berlangsung akan lebih efektif dan efisien.

Perencanaan strategis Sistem Informasi Teknologi Informasi dalam sebuah organisasi merupakan proses yang berkelanjutan dimana terdapat perubahanperubahan yang berkala dalam jangka waktu tertentu yang akan perlu sering diperbarui secara teratur sebagai respon terhadap dorongan eksternal, peluang dan kebutuhan bisnis, rencana kerja yang terjadwal, budaya organisasi dan kemanfaatan yang diperoleh dari penerapan strategi itu sendiri.

$$
\text { Apabila sebuah organisasi telah }
$$
mengimplementasikan teknologi informasi pada setiap aktivitas bisnisnya, maka dibutuhkan adanya perencanaan strategis Sistem Informasi. Investasi teknologi tanpa perancangan bisa berakibat sia-sianya investasi yang dilakukan karena fungsi dan makna investasi teknologi yang tidak selaras dengan tujuan organisasi. Perencanaan strategis sistem informasi dibutuhkan untuk mempersiapkan organisasi dalam pemakaian ternologi informasinya. Perencanaan strategis yang matang harus disesuaikan dengan kebutuhan bisnis serta tujuan organisasinya.

Perencanaan Strategis Sistem Informasi Dinas Kependudukan dan Pencatatan Sipil Kota Tomohon mengacu pada Visi Misi Walikota dan Wakil Walikota Tomohon terpilih, yang memuat penjabaran Visi Misi, Tujuan, dan Sasaran yang ingin dicapai yang terurai dalam bentuk program - program dan kegiatan kegiatan yang secara sistematis disusun dan direncanakan untuk dilaksanakan dalam kurun waktu 5 (lima) tahun, dan diharapkan dengan input dana, sumber daya manusia, dan aset yang ada akan menghasilkan output dan outcomes yang menggerakkan ekonomi seluruh masyarakat dan memberikan kesejahteraan kepada seluruh masyarakat Kota Tomohon.

Penelitian ini dilakukan untuk menghasilkan sebuah rancangan strategis sistem informasi pada Dinas Kependudukan dan Pencatatan Sipil Kota Tomohon yang selaras dengan tujuan serta visi misi organisasi dalam meningkatkan kualitas pelayanan administrasi kependudukan. Penelitian ini dilakukan dengan menggunakan metode Ward and Peppard, dengan 
menerapkan beberapa tahapan analisis seperti, analisis SWOT (Strength, Weakness, Opportunity, Threat), analisis Value Chain, Mc Farlan Strategic Grid.

Penelitian mengenai perencanaan strategis sistem informasi sudah sering dilakukan oleh beberapa peneliti terlebih dahulu, maka terdapat beberapa penelitian yang relevan dijadikan sebagai acuan pada penelitian ini, sebagai berikut:

Penelitian tentang perencanaan strategis sistem informasi yang dilakukan oleh Suryanto Nugroho, Luqman Hakim, dan Sigit Hadi Waluyo dengan judul "Perancangan Strategis Sistem Informasi Rumah Sakit Type B Menggunakan Metode Ward And Peppard". Penelitian tersebut menggunakan metode Ward and Peppard sedangkan untuk teknik analisisnya menggunakan analisis five forces competitive, analisis SWOT (Strength, Weakness, Opportunity, Threat), analisis value chain serta Mc Farlan's Strategic grid. Hasil dari penelitian tersebut adalah dokumen portofolio perencanaan strategis sistem informasi yang memuat strategi sistem informasi, strategi teknologi informasi dan strategi bisnis yang sesuai dengan karakteristik dan budaya organisasi rumah sakit type $\mathrm{b}$ (Nugroho, Hakim 2017).

Penelitian tentang perencanaan strategis sistem informasi yang dilakukan oleh Khairul Imtihan dengan judul "Perencanaan Strategi Sistem Informasi Pendidikan Pada Sekolah Tinggi Manajemen Informatika dan Komputer (STMIK) Lombok". STMIK Lombok dalam menjalankan operasional perguruan tinggi masih memiliki kendala. Strategi yang dilakukan untuk mengantisipasi hal tersebut sampai saat ini dirasakan masih kurang sehingga STMIK Lombok perlu merencanakan strategi sistem informasi yang mampu meningkatkan kinerja institusi pendidikan sesuai dengan visi dan misi perguruan tinggi. Proses identifikasi kebutuhan perencanaan strategis sistem informasi dipetakan menjadi 2 aktivitas yaitu aktivitas utama serta aktivitas pendukung (Imtihan 2015).

Penelitian tentang perencanaan strategis sistem informasi yang dilakukan oleh Vencias Markus Kawangung, Irya Wisnubhadra, Kusworo Anindito dengan judul "Perencanaan Strategis Sistem Informasi (Studi Kasus Di Kantor Pemberdayaan Perempuan Dan Keluarga Berencana). Penggunaan SI/TI pada Kantor Pemberdayaan Perempuan dan Keluarga Berencana Kabupaten Kepulauan Anambas belum dilakukan secara penuh dan masih banyak kegiatan yang dilakukan secara konvensional yang akibatnya tidak dapat mendukung pencapaian target dan kinerja yang optimal. Untuk mencapai tujuan organisasi maka diperlukan strategi SI/TI yang selaras dengan strategi bisnis. Penelitian menggunakan metode Ward and Peppard, dilakukan analisis lingkungan bisnis internal, lingkungan bisnis eksternal, lingkungan SI/TI internal dan lingkungan SI/TI eksternal yang menggunakan tools analisis Political, Economic, Social, Technological (PEST), SWOT, Critical Success Factor (CFS), Value Chain dan
McFarlan Strategic Grid. Hasil dari penelitian tersebut adalah portofolio aplikasi yang bisa dikembangkan oleh KPPKB Kabupaten Kepulauan Anambas untuk membantu dalam mencapai tujuan dan meningkatkan kinerja di masa yang akan datang (Kawangung, Wisnubhadra, and Anindito 2015).

\section{RUANG LINGKUP PENELITIAN}

Dalam penelitian ini permasalahan mencakup:

1. Cakupan permasalahan dalam penelitian ini adalah: Pada Dinas Kependudukan dan Pencatatan Sipil Kota Tomohon sudah menerapkan Sistem Informasi/Teknologi Informasi namun belum memiliki perencanaan strategis sistem informasi sehingga pengimplementasian masih kurang memadai. Untuk itu, dibutuhkan perencanaan strategis sistem informasi untuk menopang instansi dalam penggunaan SI/TI untuk meningkatkan pelayanan kepada masyarakat.

2. Batasan penelitian ini hanya mengacu pada penerapan rencana strategis Sistem Informasi

3. Rencana hasil yang didapatkan dari penelitian ini adalah rekomendasi portofolio aplikasi yang bisa dikembangkan untuk 4 tahun ke depan.

\section{BAHAN DAN METODE}

Berikut disajikan bahan kajian, metode serta tahapan penelitian yang dilakukan.

\subsection{Sistem Informasi}

Menurut Alter (1992) Sistem Informasi adalah kombinasi antar prosedur kerja, informasi, orang, dan teknologi informasi yang diorganisasikan untuk mencapai tujuan dalam sebuah organisasi. Sedangkan menurut Hall (2001) mengatakan bahwa Sistem informasi adalah sebuah rangkaian prosedur formal dimana data dikelompokkan, diproses menjadi informasi, dan didistribusikan kepada pemakai (Kadir, 2014).

\subsection{Perencanaan Strategis Sistem Informasi}

Perencanaan strategis sistem informasi merupakan proses identifikasi portofolio yang dikaji menjadi laporan akhir guna untuk mencapai tujuan bisnis suatu organisasi (Vicarya Widagdo and Kamisutara 2018). Perencanaan strategis SI/TI mempelajari pengaruh SI/TI terhadap kinerja bisnis dan kontribusi bagi organisasi dalam memilih langkah-langkah strategis (Anharudin 2015). Framework Ward and Peppard dimulai dari kondisi SI/TI dimasa lamu yang kurang bermanfaat begi tujuan bisnis dan menangkap peluang bisnis serta meningkstkan keunggulan kompetitif suatu organisasi karena mampu memanfaatkan SI/TI dengan maksimal (Asmara, Winarno, and Henderi 2017). Menurut Ward And Peppard (2002), perencanaan strategis sistem informasi memiliki metodologi yang berisi metode, teknis serta tools untuk mengerjakan sesuatu. Menurut Ward and Peppard (2002), SWOT merupakan sebuah alat untuk mendefinisikan kekuatan, kelemahan, kesempatan, dan 
ancaman yang ada pada sebuah perusahaan. Hubungannya adalah dengan faktor eksternal dan internal perusahaan dimana dapat menganalisis faktor internal (Strength and Weakness) sehingga dapat di maksimalkan kekuatannya dan meminimalkan kelemahannya. Dari faktor eksternal (Opportunity dan Threat) di mana dapat memaksimalkan peluang pasar dan meminimalisir ancaman-ancaman dari luar. Analisis value chain menggambarkan kegiatan di dalam organisasi dan sekelilingnya dan menghubungkan kegiatan-kegiatan tersebut ke dalam analisis kekuatan organisasi yang kompetitif. Oleh karena itu, value chain mengevaluasi bagian mana dari setiap aktivitas yang bisa menambah keunggulan organisasi dalam hal produk atau jasa. Analisis value chain memiliki 2 faktor pendukung, yaitu aktivitas utama dan aktivitas pendukung. Analisis Mc Farlan Stategic Grid menggambarkan kondisi organisasi saat ini, kondisi yang direncanakan serta aplikasi-aplikasi yang dianggap berpotensi dalam menunjang operasional bisnis (Ward and Peppard 2002).

\subsection{Tahapan Penelitian}

Penelitian ini dilakukan dengan menggunakan metode penelitian kualitatif. Wawancara dilakukan pada beberapa staff Disdukcapil Kota Tomohon. Penelitian ini menggunakan framework Ward and Peppard dengan berbagai metode analisis yang dilakukan seperti analisis analisis SWOT (Strength, Weakness, Opportunity, Threat), analisis Value Chain, Mc Farlan Strategic Grid. Adapun tahapan penelitian yang dilakukan ditampilkan pada gambar 1

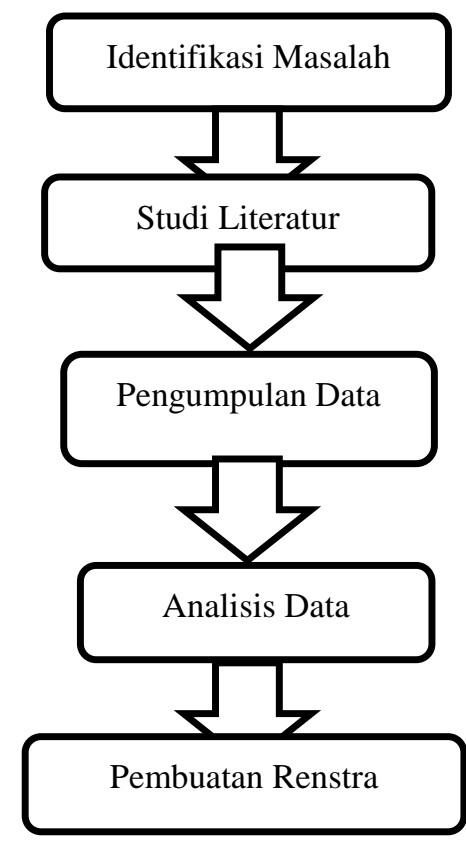

Gambar 1. Tahapan Penelitian
Keterangan Gambar 1:

1. Identifikasi Masalah

Tahap awal penelitian ini adalah mengidentifikasi masalah yang dihadapi oleh Disdukcapil kota Tomohon. Cara mengidentifikasi adalah dengan melakukan wawancara kepada beberapa pegawai yang ada di Disdukcapil kota Tomohon. Masalah yang ditemukan adalah belum adanya rencana strategis (renstra) sistem informasi.

2. Studi Literatur

Tahap selanjutnya adalah melakukan studi literatur terhadap beberapa penelitian terdahulu untuk memperkaya teori dan menghasilkan pembelajaran mengenai perencanaan strategis sistem informasi.

3. Pengumpulan Data

Tahap selanjutnya adalah melakukan pengumpulan data dengan cara wawancara terhadap staff yang ada di Disdukcapil kota Tomohon.

4. Analisis Data

Tahap selanjutnya adalah melakukan analisis data yang telah dikumpulkan melalui wawancara akan diolah menjadi informasi untuk menyusun renstra.

5. Pembuatan Renstra

Tahap selanjutnya adalah melakukan penyusunan renstra berdasarkan data yang dikumpulkan. Pembuatan renstra dilakukan melalui tiga proses yaitu analisis SWOT, analisis Value Chain, dan $M c$ Farlan Strategic Grid.

\section{PEMBAHASAN}

Berikut disajikan penyusunan rencana strategis pada Dinas Kependudukan dan Pencatatan Sipil Kota Tomohon menggunakan metode Ward and Peppard

\subsection{Analisis Lingkungan Bisnis Internal/Eksternal}

Berdasarkan hasil penelitian, tahap awal penyusunan renstra ini berupa analisis SWOT (Strength, Weakness, Opportunity, Threats) yang dilakukan untuk mengetahui kekuatan, kelemahan, peluang, serta ancaman dengan melihat lingkungan bisnis internal dan eksternal. Analisis faktor internal menggunakan metode SWOT yaitu dengan melihat kekuatan serta kelemahan organisasi. Sedangkan analisis faktor eksternal menggunakan metode SWOT adalah dengan melihat peluang dan ancaman yang datang dari luar organisasi. Berikut hasil analisis yang dilakukan ditampilkan pada tabel 1 . 
Tabel 1. Analisis SWOT pada Dinas Kependudukan Dan Pencatatan Sipil Kota Tomohon

\begin{tabular}{|c|c|}
\hline Strength & Weakness \\
\hline $\begin{array}{l}\text { 1. Tersedianya anggaran } \\
\text { pendanaan yang } \\
\text { konsisten } \\
\text { 2. Letak kantor } \\
\text { disdukcapil strategis } \\
\text { 3. Keamanan data } \\
\text { terjamin } \\
\text { 4. Computerized }\end{array}$ & $\begin{array}{ll}\text { 1. } & \text { Lokasi parkir sempit } \\
\text { 2. Kurangnya pegawai } \\
\text { sehingga antrian panjang } \\
\text { 3. } \\
\text { Ruang tunggu kurang luas } \\
\text { sehingga banyak } \\
\text { masyarakan yang } \\
\text { menunggu diluar } \\
\text { 4. Belum optimalnya sarana } \\
\text { dan prasarana pendukung } \\
\text { pelayanan administrasi }\end{array}$ \\
\hline Opportunity & Threat \\
\hline $\begin{array}{l}\text { 1. } \begin{array}{l}\text { Mendapat dukungan } \\
\text { penuh dari pemerintah } \\
\text { daerah dan pemerintah } \\
\text { pusat }\end{array} \\
\text { 2. } \begin{array}{l}\text { Semakin } \\
\text { berkembangnya } \\
\text { teknologi informasi }\end{array}\end{array}$ & $\begin{array}{l}\text { 1. Masih adanya tanggapan } \\
\text { dari masyarakat bahwa } \\
\text { administrasi Negara } \\
\text { kurang penting }\end{array}$ \\
\hline
\end{tabular}

Keterangan pada Tabel 1:

Strength :

1. Tersedianya anggaran pendanaan yang konsisten, hal tersebut menjadi kekuatan bagi Disdukcapil karena dengan anggaran yang konsisten maka setiap kebutuhan dari Disdukcapil untuk memperlancar proses pelayanannya dapat terpenuhi dengan maksimal.

2. Letak kantor Disdukcapil strategis, hal tersebut menjadi kekuatan bagi Disdukcapil karena dengan lokasi yang strategis tentu mempermudah akses masyarakat ke Disdukcapil karena lokasi kantor biasa dilewati oleh angkutan umum.

3. Keamanan data terjamin, hal tersebut menjadi kekuatan bagi Disdukcapil karena data masyarakat tidak akan bocor ke pihak luar.

4. Computerized, menjadi kekuatan bagi Disdukcapil karena dengan konsep yang terkomputerisasi maka pekerjaan yang terselesaikan dengan lebih efektif dan efisien.

Weakness :

1. Lokasi parkir sempit, hal tersebut menjadi kelemahan pada Disdukcapil karena banyak warga yang membawa kendaraan namun kesulitan saat mencari parkir.

2. Kurangnya pegawai sehingga antrian panjang, hal tersebut menjadi kelemahan bagi Disdukcapil karena banyak masyarakat yang ingin mengurus dokumen negara tapi karena antrian yang panjang serta ada pekerjaan masing-masing sehingga masyarakat sering menunda-nunda.

3. Ruang tunggu kurang luas sehingga banyak masyarakat yang menunggu diluar, hal tersebut menjadi kelemahan Disdukcapil karena masyarakat dang antri diluar tidak bisa mendengar dengan jelas saat nomor antrian disebutkan pegawai.
4. Belum optimalnya sarana dan prasarana pendukung pelayanan administrasi, hal tersebut menjadi kelemahan pada Disdukcapil karena dapat menurunkan kualitas pelayanan masyarakat.

Opportunity :

1. Mendapat dukungan penuh dari pemerintah daerah dan pusat, hal tersebut menjadi peluang bagi Disdukcapil karena dengan adanya dukungan dari pemerintah daerah dan pusat, maka pelayanan pada Disdukcapil memiliki kesempatan untuk berkembang lebih besar.

2. Semakin berkembangnya teknologi informasi, hal tersebut menjadi peluang bagi Disdukcapil karena dengan perkembangan teknologi informasi yang semakin pesat maka proses kerja pada Disdukcapil bisa menghemat waktu dan kualitas pelayanan lebih baik.

Threat:

Masih adanya tanggapan dari masyarakat bahwa dokumen negara kurang penting, hal tersebut menjadi ancaman bagi Disdukcapil karena pada dasarnya dokumen kenegaraan memang penting bagi setiap warga negara, dan sudah menjadi tugas Disdukcapil untuk menghimbau masyarakat agar memiliki dokumen kenegaraan. Namun, jika banyak masyarakat yang tidak memiliki dokumen kenegaraan berarti tugas Disdukcapil tidak terlaksana dengan baik.

Analisis value chain adalah analisis yang dilakukan untuk untuk memetakan seluruh proses bisnis yang ada di Disdukcapil. Analisis value chain dilakukan untuk melihat proses kerja dari Disdukcapil Kota Tomohon. Analisa ini bertujuan untuk mengelompokkan aktivitasaktivitas yang ada pada Disdukcapil ke dalam dau aktivitas besar yaitu aktivitas utama dan aktivitas pendukung. Berikut adalah analisis value chain yang ditampilkan pada gambar 2

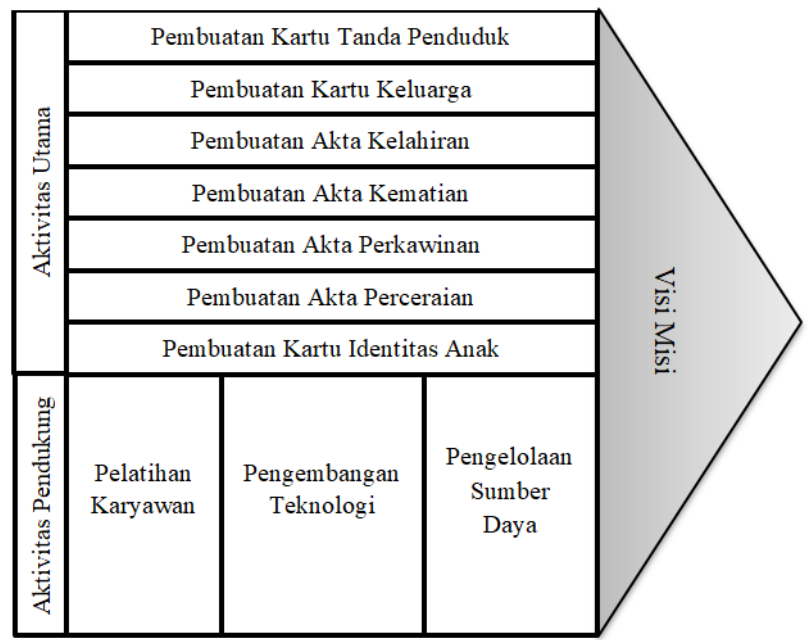

Gambar 2. Analisis Value Chain pada Disdukcapil 
Berdasarkan Gambar 2 analisis value chain berisi:

1. Aktivitas utama (Main Activity) terdiri dari:

1) Pembuatan Kartu Tanda Penduduk

2) Pembuatan Kartu Keluarga

3) Pembuatan Akta Kelahiran

4) Pembuatan Akta Kematian

5) Pembuatan Akta Perkawinan

6) Pembuatan Akta Perceraian

7) Pembuatan Kartu Identitas Anak

2. Aktivitas pendukun (Support Activity) terdiri dari:

1) Pelatihan Karyawan

2) Pengembangan Teknologi

3) Pengelolaan Sumber Daya

\subsection{Analisis Lingkungan SI Internal/Eksternal}

Selanjutnya melakukan analisis terhadap kondisi SI secara internal. Berikut adalah daftar SI yang digunakan oleh Disdukcapil ditampilkan pada tabel 2

Tabel 2. Sistem Informasi yang digunakan di Disdukcapil Kota Tomohon

\begin{tabular}{|c|c|c|c|}
\hline No & $\begin{array}{ll}\text { Nama } & \text { Sistem } \\
\text { Informasi } & \\
\end{array}$ & Pengguna & $\begin{array}{l}\text { Jenis } \\
\text { Aplikasi }\end{array}$ \\
\hline 1. & $\begin{array}{l}\text { SIAK Konsolidasi } \\
\text { Pusat Versi } 3.1\end{array}$ & $\begin{array}{l}\text { Bidang Data dan } \\
\text { Informasi }\end{array}$ & WEB \\
\hline 2. & SIAK Versi 7.1 & $\begin{array}{l}\text { Bidang pelayanan } \\
\text { pendaftaran }\end{array}$ & WEB \\
\hline 3. & $\begin{array}{l}\text { SIAK } \\
\text { BENROLLER } \\
\text { Versi } 4.0 \\
\end{array}$ & $\begin{array}{l}\text { Seksi Kartu tanda } \\
\text { penduduk }\end{array}$ & Desktop \\
\hline 4. & $\begin{array}{l}\text { SIAK } \\
\text { BCardMGMT Versi } \\
5.0\end{array}$ & $\begin{array}{l}\text { Seksi Kartu } \\
\text { Tanda Penduduk }\end{array}$ & Desktop \\
\hline 5. & $\begin{array}{ll}\text { SIMDA } & \text { Gaji } \\
\text { Taspen } & \\
\end{array}$ & Karyawan & WEB \\
\hline 6. & SIMDA Keuangan & $\begin{array}{l}\text { Bagian } \\
\text { Perencanaan dan } \\
\text { Keuangan }\end{array}$ & Desktop \\
\hline 7. & SIMDA Barang & $\begin{array}{l}\text { Bagian Umum } \\
\text { dan Kepegawaian }\end{array}$ & Desktop \\
\hline 8. & SI Kepegawaian & $\begin{array}{l}\text { Bagian Umum } \\
\text { dan Kepegawaian }\end{array}$ & Desktop \\
\hline
\end{tabular}

Keterangan tabel 2:

1. SIAK Konsolidasi Pusat Versi 3.1

SIAK Konsolidasi Pusat Versi 3.1 ini bertujuan untuk mentransfer data pencatatan sipil dari Disdukcapil Kota Tomohon ke pusat. Pada aplikasi ini juga dapat diketahui kondisi jaringan pada lokasi yang akan di transfer data.

2. SIAK Versi 7.1

SIAK Versi 7.1 ini bertujuan untuk pencetakan pendaftaran penduduk dan pencatatan sipil. Pada aplikasi ini tempat dibuatkannya segala jenis akta.

3. SIAK BENROLLER Versi 4.0

SIAK BENROLLER Versi 4.0 ini bertujuan untuk proses perekaman E-KTP mulai dari pengisian biodata masyarakat, perekaman foto serta tanda tangan masyarakat.
4. SIAK BCardMGMT Versi 5.0

SIAK BCardMGMT Versi 5.0 ini bertujuan untuk proses percetakan E-KTP.

5. SIMDA Gaji Taspen

SIMDA Gaji Taspen merupakan SI yang mengelolah gaji karyawan Disdukcapil untuk mempermudah tugas Satuan Kerja Pengelolaan Keuangan Daerah (SKPKD), SIMDA ini bertujuan untuk mengelolah gaji yang diterima, pembagain slip gaji, serta untuk perekapan.

6. SIMDA Keuangan

SIMDA Keuangan merupakan SI yang mengatur dan mencatat dana yang masuk serta dana yang keluar untuk operasional Disdukcapil Kota Tomohon.

7. SIMDA Barang

SIMDA Barang merupakan SI yang mencatat barang-barang inventaris yang dimilikin oleh Disdukcapil

8. SI Kepegawaian

SI Kepegawaian merupakan SI yang mencatat biodata karyawan, jabatan serta absensi karyawan.

\subsection{Portofolio Aplikasi}

Setelah diketahui aplikasi apa saja yang dipakai oleh Disdukcapil, dapat dilakukan pemetaan Mc Farlan Strategic Grid. Metode tersebut digunakan untuk memetakan kontribusi setiap SI terhadap organisasi. Pemetaan dilakukan menjadi 4 kuadtan yaitu key operational, strategic, support dan high potential. Berikut hasil pemetaannya yang ditampilkan pada tabel 3

Tabel 3. Strategic Grid Mc Farlan pada Disdukcapil Kota Tomohon

\begin{tabular}{|c|c|}
\hline Strategic & High Potential \\
\hline 1. SIMDA Keuangan & 1. SIMDA Barang \\
& \\
\hline 1. SIMDA Gaji Taspen & 1. SIAK Konsolidasi \\
2. SI Kepegawaian & Pusat Versi 3.1 \\
& 2. SIAK Versi 7.1 \\
& 3. SIAK BENROLLER \\
& Versi 4.0 \\
& 4. SIAK BCardMGMT \\
& Versi 5.0 \\
\hline & Key Operational \\
\hline
\end{tabular}

Keterangan Tabel 3 :

1. Kuadran 1 merupakan kuadran Strategic. Kuadran Strategic berisi apikasi apa saja yang digunakan oleh organisasi untuk menopang organisasi dimasa mendatang. Aplikasi yang dikategorikan dalan kuadran ini adalah SIMDA Keuangan.

2. Kuadran 2 merupakan kuadran High Potential.Kuadran High Potential berisi aplikasi apa saja yang nantinya akan berguna dan penting di masa 
depan. Aplikasi yang dikategorikan dalam kuadran ini adalah SIMDA Barang.

3. Kuadran 3 merupakan kuadran Key Operational. Kuadran Key Operational berisi aplikasi yang paling dibutuhkan organisasi di masa sekarang. Aplikasi yang dikategorikan pada kuadran ini adalah SIAK Konsolidasi Pusat Versi 3.1, SIAK Versi 7.1, SIAK BENROLLER Versi 4.0, SIAK BCARDMGMT Versi 5.0.

4. Kuadran 4 merupakan kuadran Support. Kuadran Support berisi aplikasi pendukung yang berguna namun bukan menjadi aplikasi utama untuk mencapai kesuksesan bisnis bersama. Aplikasi yang dikategorikan pada kuadran ini adalah SIMDA Gaji Taspen, SI Kepegawaian.

Dari hasil analisis yang dilakukan dapat disimpulkan usulan aplikasi untuk Dinas Kependudukan dan Pencatatan Sipil Kota Tomohon yang ditampilkan pada tabel 4

Tabel 4. Usulan Sistem Informasi Pada Disdukcapil

\begin{tabular}{|l|l|l|}
\hline NO & Usulan SI & Pengguna \\
\hline 1. & SI Administrasi & $\begin{array}{l}\text { Bagian Pelayanan } \\
\text { Pendaftaran }\end{array}$ \\
\hline 2. & Website Disdukcapil & $\begin{array}{l}\text { Bagian Data Dan } \\
\text { Informasi }\end{array}$ \\
\hline 3. & SI Surat & $\begin{array}{l}\text { Bagian Data Dan } \\
\text { Informasi }\end{array}$ \\
\hline
\end{tabular}

Keterangan Tabel 4:

1. SI Administrasi.

Disdukcapil direkomendasikan untuk membuat SI Administrasi karena pada Disdukcapil masih menggunakan proses administrasi manual seperti menggunakan nomor antrian menggunakan kertas dan saat giliran tiba akan dipanggil oleh pegawai Disdukcapil. Tujuan dari pembuatan SI Administrasi ini adalah untuk menghemat waktu saat mendaftar dan mengambil nomor antrian.

2. Website Disdukcapil

Disdukcapil direkomendasikan untuk membuat website karena selama ini proses penyampaian informasi seperti kelengkapan dokumen apa saja yang harus dibawa saat mengurus KTP hanya ditempelkan di papan pengumuman pada kantor Disdukcapil. Tujuan dari pembuatan website ini adalah agar masyarakat tidak perlu ke kantor Disdukcapil terlebih dahulu untuk mengetahui informasi-informasi tersebut.

3. SI Surat

SI Surat direkomendasikan pada Disdukcapil untuk dibangun karena selama ini setiap surat yang masuk dan keluar hanya dituliskan saja pada buku dan sewaktu-waktu buku tersebut bisa rusak atau hilang. Tujuan dari pembuatan SI surat ini adalah untuk meminimalisir terjadinya kehilangan surat, serta agar surat yang masuk dan keluar lebih terorganisir.

\subsection{Rencana Implementasi}

Berdasarkan hasil pemetaan dapat dilakukan rencana implementasi untuk 4 tahun ke depan, sebagai berikut:

Tabel 5. Rencana Implementasi SI pada Disdukcapil

\begin{tabular}{|c|c|c|c|c|}
\hline \multirow{3}{*}{$\begin{array}{l}\text { Nama SI } \\
\text { SIAK } \\
\text { Konsolidasi } \\
\text { Pusat Versi } 3.1 \\
\text { SIAK Versi } 7.1\end{array}$} & 2020 & 2021 & 2022 & 2023 \\
\hline & & & & \\
\hline & & & & \\
\hline $\begin{array}{l}\text { SIAK } \\
\text { BENROLLER } \\
\text { Versi } 4.0\end{array}$ & & & & \\
\hline $\begin{array}{l}\text { SIAK } \\
\text { BCardMGMT } \\
\text { Versi } 5.0\end{array}$ & & & & \\
\hline SI Administrasi & & & & \\
\hline $\begin{array}{l}\text { SIMDA } \\
\text { Keuangan } \\
\end{array}$ & & & & \\
\hline $\begin{array}{l}\text { Website } \\
\text { Disdukcapil }\end{array}$ & & & & \\
\hline $\begin{array}{ll}\text { SIMDA } & \text { Gaji } \\
\text { Taspen } & \end{array}$ & & & & \\
\hline SI Kepegawaian & & & & \\
\hline SI Surat & & & & \\
\hline SIMDA Barang & & & & \\
\hline
\end{tabular}

Keterangan Tabel 5:

1. Prioritas \#1 : Key Operational

Tahap pertama yang harus dikembangkan adalah SIAK Konsolidasi Pusat Versi 3.1, SIAK Versi 7.1, SIAK BENROLLER Versi 4.0, SIAK BCardMGMT Versi 5.0, SI Administrasi karena aplikasi-aplikasi tersebut merupakan kunci keberhasilan pada Disdukcapil.

2. Prioritas \#2 : Strategic

Tahap kedua yang harus dikembangkan adalah SIMDA Keuangan dan Website Disdukcapil karena aplikasi-aplikasi ini sangat berpengaruh dalam kelangsungan proses bisnis Disdukcapil.

3. Prioritas \#3 : Support

Tahap ketiga yang harus dikembangkan adalah SIMDA Gaji Taspen, SI Kepegawaian, SI Surat karena aplikasi-aplikasi tersebut yang membantu proses bisnis pada Disdukcapil.

4. Prioritas \#4 : High Potential

Tahap keempat yang harus dikembangkan adalah SIMDA Barang karena aplikasi ini akan berpenngaruh dalam membantu proses bisnis berjalan dengan baik di masa mendatang.

\section{KESIMPULAN}

Berdasarkan hasil penelitian dapat disimpulkan bahwa Disdukcapil sudah menerapkan SI/TI dalam menunjang aktivitas bisnisnya. Untuk itu, Disdukcapil perlu melakukan analisa kondisi SI/TI secara berkala dan membuat perancangan strategis sistem informasi agar dapat memberikan kejelasan arah pengembangan sistem 
informasi kedepan sesuai dengan kebutuhan bisnis Disdukcapil. Peracangan Renstra yang dilakukan menghasilkan beberapa usulan sistem informasi seperti SI Administrasi, SI Surat dan Website Disdukcapil yang diharapkan dapat membantu Disdukcapil dalam mencapai tujuan dan sasaran bisnis yang telah ditetapkan serta meningkatkan pelayanan publik.

\section{SARAN}

Saran kedepannya untuk peneliti selanjutnya adalah agar merancangkan renstra yang sesuai dengan tujuan bisnis organisasi. Dikarenakan penelitian ini hanya difokuskan pada pengembangan Sistem Informasi, maka untuk penelitian selanjutnya disarankan untuk mengkaji aspek yang lain.

\section{DAFTAR PUSTAKA}

Anharudin. 2015. "Perencanaan Strategis Sistem Informasi Untuk Meningkatkan Pelayanan Menggunakan Metode Ward And Peppard ( Studi Kasus : Pt Pos Indonesia Cilegon - Banten)." Jurnal PROSISKO 2 (2): 1-4. http://ejurnal.lppmunsera.org/index.php/PROSISKO/articl e/view/103/161.

Asmara, Jimi, Wing Wahyu Winarno, and - - Henderi. 2017. "Perancangan Strategis Sistem Informasi Pada Stikom Artha Buana Kupang NTT." Techno.Com $16 \quad$ (4): 387-400. https://doi.org/10.33633/tc.v16i4.1491.

Imtihan, Khairul. 2015. "Perencanaan Strategi Sistem Informasi Pendidikan Pada Sekolah Tinggi Manajemen Informatika Dan Komputer ( STMIK ) Lombok." Bianglala Informatika 3 (2): 73-78. https://ejournal.bsi.ac.id/ejurnal/index.php/Bianglal a/article/view/584.

Kadir 2014:218, Elen Vanessa Costa Da Silva, Dyule Anne Correa Martins, Ronaldo Melquides Monteiro Pimentel Junior, Eko Kurniawan Khannedy, Al Fatta, Hanif Analisis, Perancangan Sistem, Informasi Yogyakarta, and Addison Wesley Harlow. 2014. "SI Abdul Kadir.Pdf." American Enterprise Institute for Public Policy Research 14 (28): https://doi.org/10.13140/2.1.2637.6328.

Kawangung, Vencias Markus, Irya Wisnubhadra, and Kusworo Anindito. 2015. "Perencanaan Strategis Sistem Informasi (Studi Kasus Di Kantor Pemberdayaan Perempuan Dan Keluarga Berencana)." PROSIDING SEMINAR NASIONALMULTI DISIPLIN ILMU\&CALL FOR PAPERS UNISBANK (SENDI_U) Kajian Multi Disiplin Ilmu Untuk Mewujudkan Poros Maritim Dalam Pembangunan Ekonomi Berbasis
Kesejahteraan Rakyat, no. Snik: 153-58. https://www.unisbank.ac.id/ojs/index.php/sendi_u/ article/view/3347.

Nugroho, Hakim, Waluyo. 2017. "Perancangan Strategis Sistem Informasi... (Nugroho Dkk.)," 128-34. https://publikasiilmiah.unwahas.ac.id/index.php/P ROSIDING_SNST_FT/article/view/1890.

Vicarya Widagdo, Sam, and Made Kamisutara. 2018. "Perencanaan Strategis Sistem Informasi Untuk Meningkatkan Layanan Pendidikan Menggunakan Metode Ward And Peppard (Studi Kasus: SMK Swasta Di Surabaya)." Seminar Nasional Aplikasi Teknologi Informasi (SNATi), 11-2018. https://journal.uii.ac.id/Snati/article/view/11123.

Ward, and Peppard. 2002. Strategic Planning for Information Systems. Journal of Information Technology. Vol. https://doi.org/10.1057/jit.1991.9.
6. 